\title{
Second look Holter ECG in neurorehabilitation
}

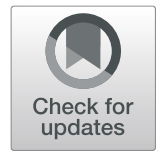

Stefan Knecht ${ }^{1,2^{*}}$ (D), Sebastian Petsch ${ }^{1,2}$, Paulus Kirchhof ${ }^{3,4}$ and Bettina Studer ${ }^{1,2}$

\begin{abstract}
Background: Many stroke survivors suffer recurrent stroke because paroxysmal atrial fibrillation (AF) was missed and no preventive anticoagulation initiated. This prospective cohort study determined the added diagnostic yield of second-look 24-h electrocardiographic recording (ECG) in a population at high risk for AF: patients who suffered a stroke of such severity that they require inpatient neurorehabilitation.

Methods: We enrolled 508 patients with ischemic stroke admitted to post-acute inpatient neurorehabilitation and determined whether AF was detected during acute care at the referring hospital. Second-look baseline and 24-h Holter ECG were then conducted during neurorehabilitation. Primary outcome was number of newly detected AF with duration of $>30 \mathrm{~s}$; secondary outcomes were number of newly detected absolute arrhythmia of 10-30 s and $<10 \mathrm{~s}$ duration. For comparison, we further enrolled 100 patients with hemorrhagic stroke without history of AF (age $=72+11$ years, $51 \%$ female).

Results: In 206 of the 508 ischemic stroke patients, AF had been detected during acute phase work-up (age = $78+10$ years, 55\% female). For the remaining 302 ischemic stroke patients, no AF was detected during acute phase work-up (age $=74+9$ years; $47 \%$ female). Second-look $24-h$ ECG showed previously missed AF of $>30 \mathrm{~s}$ in 20 of these patients, i.e. $6.6 \%$ of the sample, and shorter absolute arrhythmia in 50 patients (i.e. 16.5\%).
\end{abstract}

Conclusions: Second-look 24-Hour ECG performed during post-acute inpatient neurorehabilitation has a high diagnostic yield and should become a standard component of recurrent stroke prevention.

Keywords: Atrial fibrillation, Stroke, Neurorehabilitation, Holter ECG

\section{Introduction}

Atrial fibrillation (AF) is the leading preventable cause of recurrent stroke but easily escapes detection when paroxysmal. Moreover, short length of stay in acute stroke care adds to the diagnostic challenge. As of yet, we have no basis for anticoagulant treatment of patients with embolic stroke of undetermined source without documentation of AF [1-3]. Therefore, detection of AF remains a cornerstone for overall prevention of recurrent stroke. But, it is still unclear who should be monitored, when, and for how long [4]. Current stroke guidelines recommend 24-h electrocardiographic (ECG) monitoring [5, 6]; yet previous research indicates that a considerable portion of AF is missed with this standard work-up [7].

\footnotetext{
* Correspondence: Stefan.Knecht@stmtk.de

${ }^{1}$ Mauritius Hospital, Strümper Straße 111, 40670 Meerbusch, Germany

${ }^{2}$ Institute of Clinical Neuroscience and Medical Psychology, Medical Faculty,

Heinrich-Heine-University, Düsseldorf, Germany

Full list of author information is available at the end of the article
}

Prolonged continuous ECG monitoring with long-term non-invasive or implantable monitor systems might be a solution [7-10]. However, availability of implantable devices is still limited [11]. The current study investigated the diagnostic yield of a 2nd-look 24-h ECG conducted during post-acute inpatient neurorehabilitation. Stroke survivors who require inpatient neurorehabilitation due to severe functional impairment have a particularly high risk for AF because stroke severity is closely associated with probability of $\operatorname{AF}[12,13]$. Therefore, in terms of total diagnostic yield and cost, second-look 24-h Holter ECG in high-risk patients could compare favorably with more extensive monitoring in lower-risk populations [14].

Our primary objective was to determine the added diagnostic yield of this procedure. Therefore, we prospectively recruited and tested patients with a diagnosis

(c) The Author(s). 2019 Open Access This article is distributed under the terms of the Creative Commons Attribution 4.0 International License (http://creativecommons.org/licenses/by/4.0/), which permits unrestricted use, distribution, and reproduction in any medium, provided you give appropriate credit to the original author(s) and the source, provide a link to the Creative Commons license, and indicate if changes were made. The Creative Commons Public Domain Dedication waiver (http://creativecommons.org/publicdomain/zero/1.0/) applies to the data made available in this article, unless otherwise stated. 
of ischemic stroke for whom no AF was detected during acute care.

A secondary objective was to estimate the total rate of $\mathrm{AF}$ in ischemic stroke patients requiring inpatient neurorehabilitation. Therefore, we also recruited and tested patients with a diagnosis of ischemic stroke for whom AF was detected during acute care work-up.

Finally, to rule out that AF resulted from brain lesion rather than being the cause of ischemic strokes, we recruited and tested a comparison group of patients with hemorrhagic stroke (and no history of AF or anticoagulation treatment).

\section{Methods}

The study was performed in a single inpatient neurorehabilitation center (Mauritius Hospital Meerbusch, Germany) with 200 beds serving a catchment area of approximately 2.8 million people. Admission criteria to inpatient neurorehabilitation are substantial functional deficits corresponding to a modified Rankin score of three or worse attributable to acute neurological disease with a potential for improvement.

We prospectively included consecutive patients with ischemic or hemorrhagic strokes over an 18-months period. All survivors of acute ischemic or hemorrhagic stroke admitted to our center after hospital-based acute care were enrolled and recruitment was terminated once the pre-specified recruitment target of 600 patients was met. The number was chosen to compare with other studies in the field [9]. No further distinction was made between stroke etiologies such as lacunar or embolic because the extent of brain damage qualifying for inpatient neurorehabilitation was always compatible with a possible cardiac embolism. Exclusion criteria were primary intracranial hemorrhages with known AF or association with oral anticoagulation. Patients were assessed for demographics, acute phase (i.e. pre-rehabilitation) workup, and CHA2DS2VASc scores. Holter ECG was conducted using a commercially available 3-lead Holter monitor device (Custo-med GmbH, Germany). ECG recordings were analyzed by independent expert investigators, and blinded to clinical data using dedicated analysis software (custo-med GmbH for Windows, Version 4.3.1 Build 18,597).

AF was defined as at least one period of greater than $30 \mathrm{~s}$ duration of an absolute arrhythmia (AA) without detectable $\mathrm{P}$-waves and without a pattern more consistent with an alternative diagnosis [15]. Additionally, shorter arrhythmias were analyzed and classified as short atrial arrhythmias, i.e. of 10 to $30 \mathrm{~s}$ duration, or as atrial runs, i.e. of less than $10 \mathrm{~s}$ duration, because atrial arrhythmias of less than $30 \mathrm{~s}$ duration have been associated with increased stroke risk and are often used in clinical decision-making $[9,16]$.
Analysis of variance, chi-square tests, t-tests for independent samples (two-sided, $\alpha=.05$ ) and logistic regression were used for statistical analysis, performed in SPSS (Version 22).

\section{Ethics committee approval}

This research was approved by the Independent Ethics Committee of the Heinrich Heine University Düsseldorf, Germany (protocol no 4670).

\section{Role of the funding source}

This study was funded by the Mauritius Hospital Meerbusch, a non profit institution. The funder was not involved in the design or conduct of the study or the preparation of this manuscript (Fig. 1).

\section{Results}

\section{Group classification}

A total of 608 patients were entered in the analysis, of which 508 had ischemic stroke and 100 had hemorrhages (=comparison group). During acute care, a diagnosis of AF had been established in 206 of patients with ischemic stroke (i.e. in $40.5 \%$ of cases), whereas no AF had been detected during acute care in the remaining 302 of patients with ischemic stroke. The mean latency between stroke and admission to neurorehabilitation was 24 days in both groups with ischemic stroke and 26 days in patients with hemorrhage.

Demographic characteristics, concomitant conditions and cardiovascular risk as estimated by the $\mathrm{CHA}_{2} \mathrm{DS}_{2-}$ VASc score are displayed in Table 1. Ischemic stroke patients with AF established during acute care were significantly older than ischemic stroke patients without a diagnosis of AF (delta $=3.5$ years, LDS, $p=0.02$ ) and patients with cerebral hemorrhage (delta $=6.2$ years, $p<.001)$. Furthermore, ischemic stroke patients with AF established during acute care had a higher total $\mathrm{CHA}_{2} \mathrm{DS}_{2-}$ VASc score than patients without a diagnosis of $\mathrm{AF}$ (delta $=0.15, \mathrm{p}=0.02$ ) or with cerebral hemorrhage $($ delta $=2.74, p<.001)$. Meanwhile, ischemic stroke patients without $\mathrm{AF}$ established during acute care were older (delta $=2.6$ years, $p=.03$ ) and had a higher $\mathrm{CHA}_{2} \mathrm{DS}_{2}$ VASc score (delta $=2.5, \mathrm{p}<.001)$ than patients with cerebral hemorrhage.

\section{Added diagnostic yield of post-acute second-look 24-h ECG}

Second-look baseline ECG during neurorehabilitation found AF in 3 of the 302 patients with ischemic stroke for whom no AF was found during acute-care work-up. Second look 24-h Holter ECG revealed AF in an additional 17 patients of this group. In total, previously undetected AF was thus found in $6.6 \%$ of patients with ischemic stroke admitted without a diagnosis of AF. A 


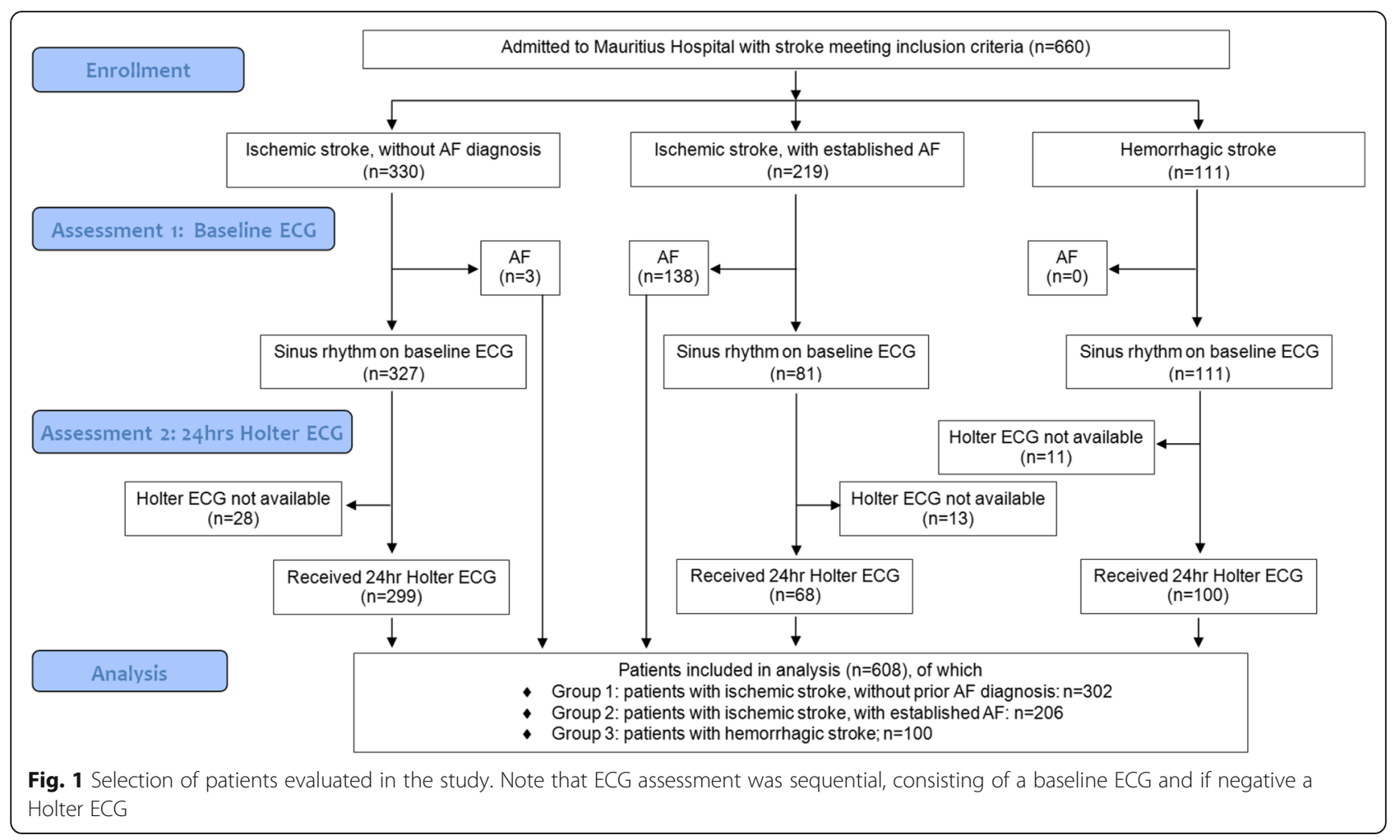

further 11 patients (i.e. 3.6\%) showed absolute arrhythmia of $10-30 \mathrm{~s}$ on the $24-\mathrm{h}$ and 39 patients (i.e. $12.9 \%$ ) showed absolute arrhythmia of $<10 \mathrm{~s}$ on the $24-\mathrm{h}$ Holter ECG.

Patients for whom AF was newly detected during this second-look ECG work-up were moderately, but not significantly, older (delta $=3.2$ years, $p=.07$ ) than patients for whom AF was not detected in either the acute phase nor on second-look ECG. Total $\mathrm{CHA}_{2} \mathrm{DS}_{2} \mathrm{VASc}$ score (delta $=.29, p=.32)$ and prevalences of the individual risk factors comprised in the $\mathrm{CHA}_{2} \mathrm{DS}_{2}$ VASc score did not differ between the two groups (all $\mathrm{X}^{2}<1.45, p>.25$ ).

\section{Total rate of AF in ischemic stroke patients requiring inpatient neurorehabilitation}

For 206 of the 508 patients with ischemic stroke admitted to our neurorehabilitation center, AF was already confirmed during the acute-care work-up. Details of the diagnostic work-up during acute care in referring hospital are provided in Table 2. Together with the 20 newly detected cases, the total rate of AF in ischemic stroke patients requiring inpatient neurorehabilitation was therefore determined as 226 out of 528 patients or $44.5 \%$ of the cohort (see Fig. 2).

Across all ischemic stroke patients, AF (diagnosed during acute care and/or neurorehabilitation) showed a significant association with age (logistic regression with age as predictor and AF (yes/no) as independent variable; $\beta=.05, p<.0001)$. The highest prevalence of AF was observed for patients aged 80 to 89 years and was $62 \%$ (see Fig. 3).

\section{Sensitivity: results of post-acute work-up in patients admitted with AF diagnosis}

In the 206 patients with ischemic stroke in whom AF had been detected during acute care, second-look baseline ECG revealed AF in 138 cases (i.e. $67 \%$ of the sample). A subsequent 24-h Holter ECG confirmed AF in a further 34 patients (i.e. $16.5 \%$ of the sample). In the remaining 34 individuals (i.e. $16.5 \%$ of the sample), second-look 24-h ECG did not show AF. These results again demonstrate that (paroxysmal) AF is sometimes missed in a 24-h ECG.

\section{Results of post-acute 24-h ECG in the comparison group with hemorrhagic group}

In patients with hemorrhagic stroke, 24-h ECG performed during post-acute neurorehabilitation revealed $\mathrm{AF}$ in 2 patients (i.e. $2 \%$ of cohort) and absolute arrhythmia of $<10 \mathrm{~s}$ in 6 patients (6\%). Absolute arrhythmia of 10-30 s did not occur in this cohort.

\section{Discussion}

Main findings

This prospective evaluation investigated the diagnostic yield of second-look 24-h ECG in 508 consecutive 
Table 1 Patient characteristics including mean $\mathrm{CHA}_{2} \mathrm{DS}_{2}$ VASc -score

\begin{tabular}{|c|c|c|c|c|}
\hline Group & $\begin{array}{l}\text { Ischemic stroke admitted to } \\
\text { neuro-rehabilitation without } \\
\text { diagnosis of AF }\end{array}$ & $\begin{array}{l}\text { Ischemic stroke admitted to } \\
\text { neuro-rehabilitation with } \\
\text { diagnosis of AF }\end{array}$ & $\begin{array}{l}\text { Hemorrhagic } \\
\text { stroke }\end{array}$ & $\begin{array}{l}\text { Group } \\
\text { comparisor }\end{array}$ \\
\hline Number of patients & 302 & 206 & 100 & \\
\hline Mean age $+\mathrm{SD}$ & $74+9$ & $78+10$ & $72+11$ & $\begin{array}{l}F=15.36 \\
P=.001^{a}\end{array}$ \\
\hline \multicolumn{5}{|c|}{ Prevalence of stroke risk factors on $\mathrm{CHA}_{2} \mathrm{DS}_{2} \mathrm{VASC}$} \\
\hline Congestive heart failure & $15 \%$ & $22 \%$ & $9 \%$ & $\begin{array}{l}X^{2}=8.61 \\
p=.01^{b}\end{array}$ \\
\hline Hypertension & $95 \%$ & $98 \%$ & $86 \%$ & $\begin{array}{l}X^{2}=17.52 \\
P=.001 b\end{array}$ \\
\hline Age $>75$ years & $48 \%$ & $72 \%$ & $48 \%$ & $\begin{array}{l}X^{2}=31.41 \\
P=.001^{b}\end{array}$ \\
\hline Age $65-74$ years & $37 \%$ & $20 \%$ & $31 \%$ & $\begin{array}{l}X^{2}=15.20 \\
P=.001^{b}\end{array}$ \\
\hline Diabetes mellitus & $21 \%$ & $22 \%$ & $17 \%$ & $\begin{array}{l}X^{2}=1.02 \\
P=.60\end{array}$ \\
\hline Stroke/ TIA/ Thrombo-embolic events & $100 \%$ & $100 \%$ & $3 \%$ & $\begin{array}{l}X^{2}=586.29 \\
P=.001 b\end{array}$ \\
\hline Vascular disease & $42 \%$ & $17 \%$ & $8 \%$ & $\begin{array}{l}X^{2}=60.78 \\
P=.001 b\end{array}$ \\
\hline Female sex & $47 \%$ & $55 \%$ & $51 \%$ & $\begin{array}{l}X^{2}=3.40 \\
P=.18\end{array}$ \\
\hline \multicolumn{5}{|l|}{ Mean Total $\mathrm{CHA}_{2} \mathrm{DS}_{2}$ VASC -score } \\
\hline Mean score + SD & $5.52 \pm 1.28$ & $5.78 \pm 1.18$ & $3.03 \pm 1.30$ & $\begin{array}{l}F=182.57 \\
P=.001^{c}\end{array}$ \\
\hline
\end{tabular}

${ }^{a}$ Pairwise post-hoc comparisons revealed hemorrhagic stroke patients were younger than both ischemic stroke patient groups (LSD, ps <.02), and ischemic stroke patients admitted with established AF were significantly older than ischemic stroke patients without AF documented during acute phase work-up (LSD, $p=.001$ )

${ }^{b}$ For Congestive heart failure, Hypertension and Stroke/TIA/Thrombo-embolic events the group effect was driven by a lower prevalence in the hemorrhagic stroke group compared to the two ischemic stroke groups. For Vascular disease sex the group effect was mainly driven by the ischemic group without established AF. For the two Age-related risk factors and Female sex the group effect was mainly driven by the ischemic group with established AF

' Post-hoc comparisons showed that hemorrhagic stroke patients had a lower score than the two ischemic groups (LSD, ps <.03), and that ischemic stroke patients with no documentation of AF had a lower score than those with established AF $(\mathrm{LSD}, \mathrm{ps}=.02)$

patients with ischemic stroke selected on the basis of requiring inpatient neurorehabilitation. Stroke patients requiring inpatient neurorehabilitation are older and more severely affected than unselected stroke survivors. Given that both of these factors are associated with increased risk for AF [12], we postulated that stroke patients requiring inpatient neurorehabilitation constitute a high-risk cohort. Our data confirm this hypothesis. The total (combined) prevalence of $\mathrm{AF}$ in our neurorehabilitation cohort of ischemic stroke patients was $44.5 \%$ (226 out of 508 patients). In comparison, previously reported prevalence of AF based on 24-74h of ECG monitoring in unselected samples of ischemic stroke or ischemic transient attack survivors typically ranged between 5 and $10 \%[9,17-21]$.

The added diagnostic yield of second-look ECG workup during post-acute care, consisting of a baseline ECG and subsequent 24-h Holter ECG, in this high-risk cohort was also impressive: AF was detected in $6.6 \%$ of ischemic stroke patients for whom acute-phase work-up found no AF. In comparison, in a cohort of unselected stroke patients who were re-assessed by second-look 24h ECG within 6 month of their stroke in the EMBRACE control arm, the rate of newly detected AF was 3.2\% [8], approximately half of that found here. Similarly, a recent prospective multicenter trial showed that prolonging acute-phase Holter ECG monitoring from $24 \mathrm{~h}$ to $72 \mathrm{~h}$ resulted in an added detection of $1.7 \%$ cases [9], 4-5 times less than that found in the current study. Moreover, our detection rate is five times higher than that found in unselected stroke patients re-assessed at scheduled and unscheduled visits with ECG monitoring performed at the discretion of stroke specialists in the CRYSTAL-AF control cohort [7].

\section{Length of arrhythmias}

The diagnosis of paroxysmal AF requires the detection of an arrhythmia of $30 \mathrm{~s}$ or longer [22]. This definition is based on convention, but has been widely accepted. Nonetheless, observational data suggest that shorter 
Table 2 ECG during acute care in referring hospital

\begin{tabular}{|c|c|c|c|c|}
\hline \multirow[t]{2}{*}{ Group } & \multicolumn{2}{|c|}{ Ischemic stroke admitted without diagnosis of AF } & \multirow[b]{2}{*}{$\begin{array}{l}\text { Ischemic } \\
\text { stroke } \\
\text { admitted } \\
\text { with } \\
\text { diagnosis } \\
\text { of AF }\end{array}$} & \multirow{2}{*}{$\begin{array}{l}\text { Hemorrhagic } \\
\text { stroke }\end{array}$} \\
\hline & $\begin{array}{l}\text { no AF diagnosis during } \\
\text { re-habilitation }\end{array}$ & $\begin{array}{l}\text { newly diagnosed } \\
\text { with AF during } \\
\text { re-habilitation }\end{array}$ & & \\
\hline Number of patients & 282 & 20 & 206 & 100 \\
\hline Stroke unit acute care & $83 \%$ & $85 \%$ & $85 \%$ & $46 \%$ \\
\hline Non-stroke unit acute care & $17 \%$ & $15 \%$ & $15 \%$ & $54 \%$ \\
\hline \multicolumn{5}{|l|}{ Diagnostic work-up during acute care, as \% of sample } \\
\hline Standard ECG / of which resulted in AF diagnosis & $71 \% / 0 \%$ & $75 \% / 0 \%$ & $65 \% / 68 \%$ & $44 \% / 0 \%$ \\
\hline Holter ECG / of which resulted in AF diagnosis & $51 \% / 0 \%$ & $50 \% / 0 \%$ & $63 \% / 89 \%$ & $9 \% / 0 \%$ \\
\hline Bedside monitor ECG / of which resulted in AF diagnosis & $14 \% / 0 \%$ & $5 \% / 0 \%$ & $11 \% / 90 \%$ & $5 \% / 0 \%$ \\
\hline Information missing & $16 \%$ & $15 \%$ & $15 \%$ & $50 \%$ \\
\hline \multicolumn{5}{|l|}{ Etiology according to acute care diagnosis } \\
\hline cardiogenic & $6 \%$ & $5 \%$ & $90 \%$ & \\
\hline arteriosclerotic & $63 \%$ & $65 \%$ & $5 \%$ & \\
\hline micro-angiopathy & $9 \%$ & $5 \%$ & $1 \%$ & \\
\hline not specified & $16 \%$ & $25 \%$ & $4 \%$ & \\
\hline
\end{tabular}

atrial arrhythmias identify patients with AF, and that patients with such arrhythmias have an increased risk of stroke [23-25]. Therefore, in clinical practice, many patients with briefer AF episodes after cryptogenic stroke are prescribed anticoagulant therapy - particularly by neurologists [16]. For instance, the STROKESTOP mass screening for AF study in Sweden used two episodes of irregular rhythm without p-waves of $10-29 \mathrm{~s}$ as a criterion for anticoagulation prescription [26]. Further, other studies evaluated the usefulness of oral anticoagulation in all patients with embolic stroke of unknown origin and no positive documentation of AF in 24-h ECG where many eligible patients will have undetected atrial arrhythmias or even undetected atrial fibrillation [2, 3]. Here, we thus also reported on patients with short atrial arrhythmias. We found that an additional 3.6\% of ischemic stroke patients for whom acute-care work-up showed no AF had atrial arrhythmias of 10-30s duration and an additional $12.9 \%$ had arrhythmias of less than $10 \mathrm{~s}$. All durations taken together, arrhythmias were thus found in $23 \%$, or one in four patients, of the subsample, which corresponds well with the results of a recent meta-analysis by Sposato and colleagues on prevalence of atrial arrhythmias of any length [27]. However, their meta-analysis reviewed findings from a fourstage sequential screening including inpatient serial monitoring, ambulatory Holter ECG, as well as outpatient external and implantable loop recordings. In other words, in our high risk group, $24 \mathrm{~h}$-screening provided equally high detection rates of atrial arrhythmias as extensive and invasive sequential screenings in unselected cohorts.

\section{Causality}

Differentiation between patients with AF antecedent to stroke and those with new onset AF is not feasible. Brain lesions may trigger AF $[28,29]$. Could AF in this cohort reflect an effect of brain lesion rather than of stroke cause, particularly since our patients presumably had larger lesions than unselected stroke patients? To answer this question we also assessed AF in patients with brain hemorrhages without a history of AF, as an internal control for the effect of brain lesion unrelated to cardiogenic embolism. For this group, detection rate of AF in 24-h ECG during neurorehabilitation was only $2 \%$, i.e. three times less often than in patients with ischemic stroke. These differences did not, however, reach significance on chi-square testing for independence $(p=0.078)$. Short arrhythmia were found in $6 \%$ of hemorrhagic stroke patients and were thus also significantly rarer in hemorrhagic compared to ischemic stroke patients. These findings suggest that AF in our cohort was much more likely to be the cause for rather than a sequel of ischemic brain lesion.

\section{Limitations}

Some of our clinical data were obtained from outside acute care institutions with variability in type and documentation of the primary diagnostic work-up. In some cases, mode of ECG assessment was not reported (see 


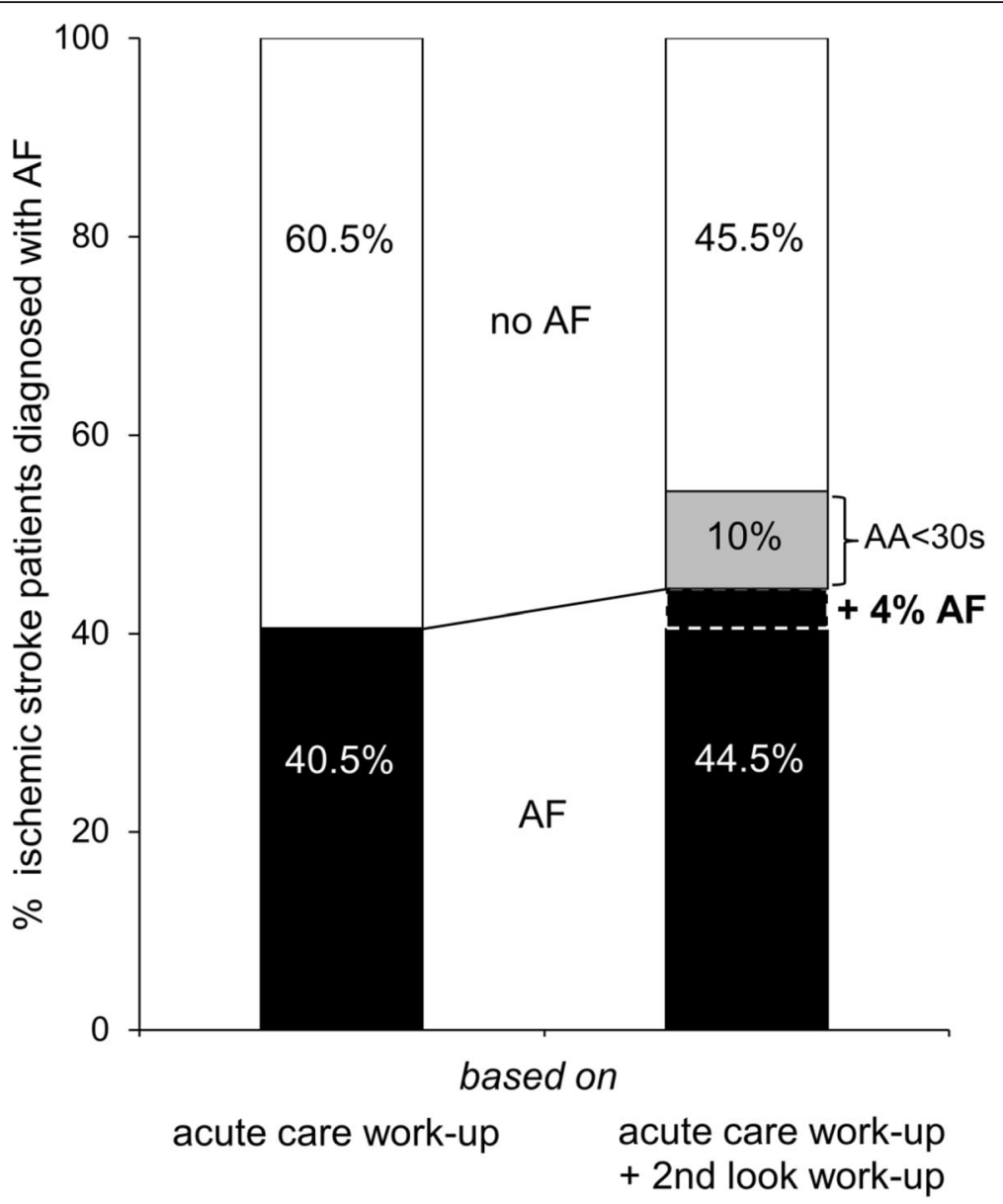

Fig. 2 Proportion of patients with ischemic stroke (total $n=508$ ) diagnosed with AF based on acute care work-up alone (left) and based on both acute care work-up and post-acute second-look ECG performed during inpatient neurorehabilitation

Table 2). Similarly, documentation of etiological classification of strokes was heterogeneous.

\section{Cost-effectiveness}

Outpatient cardiac monitoring for detection of previously missed AF in a hypothetical cohort of 70-year-old stroke survivors has been found cost-effective over a range of models based on an added diagnostic yield of $4.4 \%$ [30]. Comparable results have been obtained from the Swedish system based on use of health care resources, savings of costs and lives, and improvement of quality of life [31].

Our data did not allow for a full cost-effectiveness model. However, since inpatient second-look ECG monitoring requires less incremental logistics, allows for more timely diagnosis and treatment and provides higher detection rates, we assume that second-look 24-h ECG in inpatient neurorehabilitation is even more costeffective than outpatient monitoring.
Annual recurrence rate of up to $19 \%$ have been reported in stroke patients with AF detected after discharge [32]. Conversely, in the age group older than 75 years, anticoagulation initiated after detection of AF provides almost a $60 \%$ risk reduction of stroke relative to antiplatelet therapy $[33,34]$. Given the $6 \%$ detection rate of previously missed AF in the present study, a secondlook 24-h ECG during inpatient neurorehabilitation with appropriate subsequent treatment could therefore, over the course of five years, prevent one recurrent stroke for every 25 patients evaluated. The number needed to screen would be even lower if shorter duration atrial arrhythmias were included. Given that around $40 \%$ of ischemic stroke patients are referred to inpatient postacute rehabilitation [35], the overall impact of a secondlook ECG for AF would be substantial.

Inpatient neurorehabilitation allows for second-look etiological evaluation, management of medical complication, training of impaired functions and initiation of future care. However, as yet, diagnostic measures have 


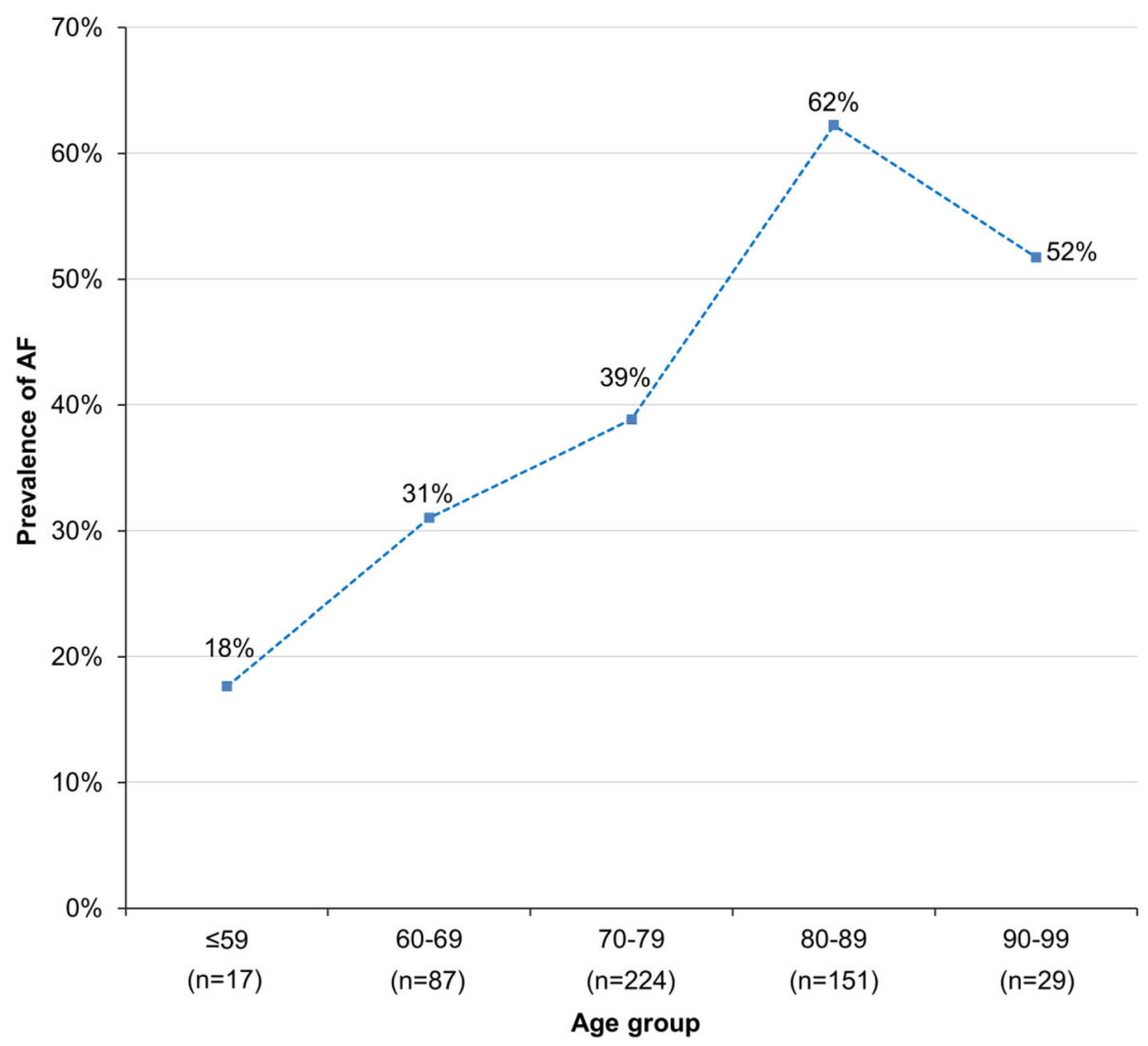

Fig. 3 Prevalence of AF (based on both acute care work-up and post-acute second-look $24 \mathrm{~h} \mathrm{ECG)} \mathrm{relative} \mathrm{to} \mathrm{age} \mathrm{(} x$-axis) in patients with ischemic stroke requiring inpatient neurorehabilitation (number of patients per age group in brackets)

neither been incorporated into guidelines for post-stroke neurorehabilitation, nor are they reimbursed. The present study demonstrates that secondary prevention of stroke could gain substantially by better use of the full chain of care.

\section{Conclusions}

A simple second-look 24-h ECG in stroke survivors during inpatient neurorehabilitation identifies more patients with previously missed AF than in most other settings and should be made a standard of care.

\section{Acknowledgements}

None

\section{Declaration of interests}

S Knecht received honoraria from Bayer. S Petsch reports no disclosures. JM UI Qamar reports no disclosures. P Kirchhof received support for research work from British Heart Foundation, European Union, German Research Foundation, Fondation Leducq, St Jude, Sanofi, Daiichi Sankyo, Cardiovascular Therapeutics, and Bristol-Myers Squibb/Pfizer. He also received honoraria and/or travel support from European Society of Cardiology, German Cardiac Society (Akademie), AFNET, different universities and academic bodies, Bayer, Boehringer, Bristol-Myers Squibb, Daiichi-Sankyo, Johnson\&Johnson, Medtronic, MSD, Pfizer, and Servier. B Studer received research support from the Mauritius Hospital and the Swiss National Science Foundation (PBSKP3 138,598).
Authors' contributions

SK designed and interpreted the study; SP carried out the data acquisition; PK contributed to the discussion and write-up; BS. analyzed and interpreted the data. All authors read and approved the final manuscript.

\section{Funding}

This study was funded by the Mauritius Hospital Meerbusch, a non-profit institution that allocates resources to research in improvements of quality of care. The funder was not involved in the design or conduct of the study or the preparation of this manuscript.

Availability of data and materials

Please contact corresponding author for data requests

Ethics approval and consent to participate

This research was approved by the Independent Ethics Committee of the Heinrich Heine University Düsseldorf, Germany (protocol no 4670)

\section{Consent for publication}

Was obtained using institutional consent forms.

\section{Competing interests}

The authors declare that above mentioned interactions do not compete with the content of the present paper.

\section{Author details}

'Mauritius Hospital, Strümper Straße 111, 40670 Meerbusch, Germany.

${ }^{2}$ Institute of Clinical Neuroscience and Medical Psychology, Medical Faculty, Heinrich-Heine-University, Düsseldorf, Germany. ${ }^{3}$ University of Birmingham, Centre of Cardiovascular Sciences and SWBH NHS trust, Birmingham, UK. 
${ }^{4}$ Department of Cardiovascular Medicine, University Hospital Münster, Münster, Germany and AFNET, Münster, Germany.

\section{Received: 6 August 2019 Accepted: 15 November 2019} Published online: 20 December 2019

\section{References}

1. Hart, R. G., Diener, H.-C., Coutts, S. B., Easton, J. D., Granger, C. B., O'Donnell, M. J., et al. (2014). Embolic strokes of undetermined source: the case for a new clinical construct. Lancet Neurol, 13, 429-438.

2. Hart, R. G., Sharma, M., Mundl, H., Kasner, S. E., Bangdiwala, S. I., Berkowitz, S. D., et al. (2018). Rivaroxaban for Stroke Prevention after Embolic Stroke of Undetermined Source. N Engl J Med, 378, 2191-2201. https://doi.org/10. 1056/NEJMoa1802686.

3. Diener, H.-C., Sacco, R. L., Easton, J. D., Granger, C. B., Bernstein, R. A. Uchiyama, S., et al. (2019). Dabigatran for Prevention of Stroke after Embolic Stroke of Undetermined Source. N Engl J Med, 380, 1906-1917. https://doi. org/10.1056/NEJMoa1813959.

4. Rabinstein, A. A. (2014). Prolonged cardiac monitoring for detection of paroxysmal atrial fibrillation after cerebral ischemia. Stroke, 45, 1208-1214. https://doi.org/10.1161/STROKEAHA.113.003389.

5. Jauch, E. C., Saver, J. L., Adams, H. P., Bruno, A., JJB, C., Demaerschalk, B. M., et al. (2013). Guidelines for the early management of patients with acute ischemic stroke: A guideline for healthcare professionals from the American Heart Association/American Stroke Association. Stroke, 44, 870-947.

6. Kernan WN, Ovbiagele B, Black HR, Bravata DM, Chimowitz MI, Ezekowitz $M D$, et al. Guidelines for the prevention of stroke in patients with stroke and transient ischemic attack: A guideline for healthcare professionals from the American Heart Association/American Stroke Association. 2014.

7. Sanna, T., Diener, H. C., Passman, R. S., Di Lazzaro, V., Bernstein, R. A., Morillo, C. A., et al. (2014). Cryptogenic stroke and underlying atrial fibrillation. $N$ Engl J Med, 370, 2478-2486. https://doi.org/10.1056/NEJMoa1313600.

8. Gladstone, D. J., Spring, M., Dorian, P., Panzov, V., Thorpe, K. E., Hall, J., et al. (2014). Atrial fibrillation in patients with cryptogenic stroke. N Engl J Med, 370, 2467-2477. https://doi.org/10.1056/NEJMoa1311376.

9. Grond, M., Jauss, M., Hamann, G., Stark, E., Veltkamp, R., Nabavi, D., et al. (2013). Improved detection of silent atrial fibrillation using 72-hour Holter ECG in patients with ischemic stroke: a prospective multicenter cohort study. Stroke, 44, 3357-3364. https://doi.org/10.1161/STROKEAHA.113.001884.

10. Hendrikx, T., Hörnsten, R., Rosenqvist, M., \& Sandström, H. (2013). Screening for atrial fibrillation with baseline and intermittent ECG recording in an outof-hospital population. BMC Cardiovasc Disord, 13, 41. https://doi.org/10. 1186/1471-2261-13-41

11. Wachter, R., \& Gröschel, K. (2017). Atrial fibrillation in high-risk patients with ischaemic stroke \&\#x2013; Authors' reply. Lancet Neurol, 16, 498. https://doi. org/10.1016/S1474-4422(17)30165-5.

12. ER, M. G., Kapral, M. K., Fang, J., Eikelboom, J. W., Conghaile, A. Ó., O'Conghaile, A., et al. (2013). Association of atrial fibrillation with mortality and disability after ischemic stroke. Neurology, 81, 825-832. https://doi.org/ 10.1212/WNL.0b013e3182a2cc15.

13. Marini, C., De Santis, F., Sacco, S., Russo, T., Olivieri, L., Totaro, R., et al. (2005). Contribution of atrial fibrillation to incidence and outcome of ischemic stroke: Results from a population-based study. Stroke, 36, 1115-1119.

14. Knecht, S., Petsch, S., \& Studer, B. (2017). Atrial fibrillation in high-risk patients with ischaemic stroke. Lancet Neurol, 16, 498. https://doi.org/10. 1016/S1474-4422(17)30172-2

15. Kirchhof, P., Auricchio, A., Bax, J., Crijns, H., Camm, J., Diener, H. C., et al. (2007). Outcome parameters for trials in atrial fibrillation: recommendations from a consensus conference organized by the German Atrial Fibrillation Competence NETwork and the European Heart Rhythm Association. Europace, 9, 1006-1023. https://doi.org/10.1093/europace/eum191.

16. Khan, M., Miller, D. J., \& Schultz, L. R. (2013). Indecision in the clinical practice of anticoagulation for brief atrial arrhythmias after cryptogenic stroke. J Stroke Cerebrovasc Dis, 22, e500-e503. https://doi.org/10.1016/j. jstrokecerebrovasdis.2013.05.019.

17. Jabaudon, D., Sztajzel, J., Sievert, K., Landis, T., \& Sztajzel, R. (2004). Usefulness of ambulatory 7-day ECG monitoring for the detection of atrial fibrillation and flutter after acute stroke and transient ischemic attack. Stroke, 35, 1647-1651.

18. Schaefer, J. R., Leussler, D., Rosin, L., Pittrow, D., \& Hepp, T. (2014). Improved detection of paroxysmal atrial fibrillation utilizing a software-assisted electrocardiogram approach. PLoS One, 9.
19. Schaer, B. A., Zellweger, M. J., Cron, T. A., Kaiser, C. A., \& Osswald, S. (2004). Value of Routine Holter Monitoring for the Detection of Paroxysmal Atrial Fibrillation in Patients With Cerebral Ischemic Events. Stroke, 35, 2003-2005. https://doi.org/10.1161/01.STR.0000117568.07678.4B.

20. Lazzaro, M. A., Krishnan, K., \& Prabhakaran, S. (2012). Detection of atrial fibrillation with concurrent Holter monitoring and continuous cardiac telemetry following ischemic stroke and transient ischemic attack. J Stroke Cerebrovasc Dis, 21, 89-93. https://doi.org/10.1016/j.jstrokecerebrovasdis. 2010.05.006.

21. Barthélémy, J. C., Féasson-Gérard, S., Garnier, P., Gaspoz, J. M., Da Costa, A., Michel, D., et al. (2003). Automatic cardiac event recorders reveal paroxysmal atrial fibrillation after unexplained strokes or transient ischemic attacks. Ann Noninvasive Electrocardiol, 8, 194-199.

22. Lévy, S. (2000). Classification system of atrial fibrillation. Curr Opin Cardiol, 15, 54-57 http://www.ncbi.n/m.nih.gov/pubmed/10666661.

23. Friberg, L., Engdahl, J., Frykman, V., Svennberg, E., Levin, L. A., \& Rosenqvist, M. (2013). Population screening of 75- and 76-year-old men and women for silent atrial fibrillation (STROKESTOP). Europace, 15, 135-140. https://doi.org/ 10.1093/europace/eus217.

24. Glotzer, T. V., Hellkamp, A. S., Zimmerman, J., Sweeney, M. O., Yee, R., Marinchak, R., et al. (2003). Atrial high rate episodes detected by pacemaker diagnostics predict death and stroke: report of the Atrial Diagnostics Ancillary Study of the MOde Selection Trial (MOST). Circulation, 107, 16141619. https://doi.org/10.1161/01.CIR.0000057981.70380.45.

25. Sposato, L. A., Cipriano, L. E., Riccio, P. M., Hachinski, V., \& Saposnik, G. (2015). Very short paroxysms account for more than half of the cases of atrial fibrillation detected after stroke and TIA: a systematic review and metaanalysis. Int J Stroke, 10, 801-807. https://doi.org/10.1111/ijs.12555.

26. Svennberg, E., Engdahl, J., Al-Khalili, F., Friberg, L., Frykman, V., \& Rosenqvist, M. (2015). Mass screening for untreated atrial fibrillation the STROKESTOP study. Circulation, 131, 2176-2184.

27. Sposato, L. A., Cipriano, L. E., Saposnik, G., Vargas, E. R., Riccio, P. M., \& Hachinski, V. (2015). Diagnosis of atrial fibrillation after stroke and transient ischaemic attack: a systematic review and meta-analysis. Lancet Neurol, 14, 377-387. https://doi.org/10.1016/s1474-4422(15)70027-x.

28. Christensen, H., Boysen, G., Christensen, A. F., \& Johannesen, H. H. (2005). Insular lesions, ECG abnormalities, and outcome in acute stroke. J Neurol Neurosurg Psychiatry, 76, 269-271. https://doi.org/10.1136/jnnp.2004.037531.

29. Sposato, L. A., Riccio, P. M., \& Hachinski, V. (2014). Poststroke atrial fibrillation: cause or consequence? Critical review of current views. Neurology, 82, 1180 1186. https://doi.org/10.1212/WNL.0000000000000265.

30. Kamel, H., Hegde, M., Johnson, D. R., Gage, B. F., \& Johnston, S. C. (2010). Cost-effectiveness of outpatient cardiac monitoring to detect atrial fibrillation after ischemic stroke. Stroke, 41, 1514-1520. https://doi.org/10. 1161/STROKEAHA.110.582437.

31. Levin, L. A., Husberg, M., Sobocinski, P. D., Kull, V. F., Friberg, L., Rosenqvist, M., et al. (2015). A cost-effectiveness analysis of screening for silent atrial fibrillation after ischaemic stroke. Europace, 17, 207-214. https://doi.org/10. 1093/europace/euu213.

32. Kamel, H., Johnson, D. R., Hegde, M., Go, A. S., Sidney, S., Sorel, M., et al. (2012). Detection of atrial fibrillation after stroke and the risk of recurrent stroke. J Stroke Cerebrovasc Dis, 21, 726-731. https://doi.org/10.1016/j. jstrokecerebrovasdis.2011.03.008.

33. Ng, K. H., Hart, R. G., \& Eikelboom, J. W. (2013). Anticoagulation in Patients Aged $\geq 75$ years with Atrial Fibrillation: Role of Novel Oral Anticoagulants. Cardiol Ther, 2, 135-149. https://doi.org/10.1007/s40119-013-0019-y.

34. van Walraven, C., Hart, R. G., Connolly, S., Austin, P. C., Mant, J., Hobbs, F. D., et al. (2009). Effect of age on stroke prevention therapy in patients with atrial fibrillation: the atrial fibrillation investigators. Stroke, 40, 1410-1416. https://doi.org/10.1161/STROKEAHA.108.526988.

35. Unrath, M., Kalic, M., \& Berger, K. (2013). Who receives rehabilitation after stroke?: Data from the quality assurance project "Stroke Register Northwest Germany". Dtsch Arztebl Int, 110, 101-107. https://doi.org/10.3238/arztebl. 2013.0101.

\section{Publisher's Note}

Springer Nature remains neutral with regard to jurisdictional claims in published maps and institutional affiliations. 